\title{
Impact of Team Diversity and Conflict on Project Performance in Indonesian Start-Ups
}

\author{
Budi Hartono $^{1}$ (D), Luthfi Dzulfikar ${ }^{1}$ (D), Retno Damayanti ${ }^{1,2}$ (iD \\ ${ }^{1}$ Universitas Gadjah Mada (Indonesia) \\ ${ }^{2}$ Sebelas Maret University (Indonesia) \\ boed@gadjahmada.edu,luthfi.t.dzulfikar@gmail.com,retno.wulan.d@mail.ugm.ac.id
}

Received: October 2019

Accepted: February 2020

\section{Abstract:}

Purpose: Based on social identity and information/decision-making theories, in this study, we developed and empirically verified a fresh theoretical model for the possible mediating effect of emotional and task conflicts on the associations between diversity (work, social, and ideological) and project performance.

Design/methodology/approach: A survey was conducted of 68 Indonesian start-up firms, which achieved a 57.6\% response rate. In total, 102 Indonesian project teams participated. Multiple team members were questioned regarding their respective teams, for a total of 395 individual respondents. An aggregation protocol was utilized to establish team-level datasets. The partial least squares (PLS) method was utilized to test our hypotheses.

Findings: The findings suggest a detrimental effect on team performance of heightened ideological polarization as indicated by emotional conflict. Moreover, work diversity was found to positively affect task conflict, but not team performance. Possible moderating variables such as cultural factors may lessen the impact.

Research limitations/implications: This study offers a fresh theoretical model pertaining to diversity, conflict, and performance. It also offers unique empirical evidence with which to examine theoretical propositions within the context of Indonesian start-ups. The sample size is rather limited for a confirmatory study even though it is substantially larger than similar past studies.

Practical implications: The findings offer practical insights for start-ups to improve their project performance by consideration of the intricate association between aspects of team diversity and conflict.

Originality/value: This study extends contemporary knowledge regarding diversity by its focus on the project context of Indonesian start-ups.

Keywords: diversity, conflict, team performance, project team effectiveness, developing countries

\section{To cite this article:}

Hartono, B., Dzulfikar, L., \& Damayanti, R. (2020). Impact of team diversity and conflict on project performance in indonesian start-ups. Journal of Industrial Engineering and Management, 13(1), 155-178. https://doi.org/10.3926/jiem.3037 


\section{Introduction}

The number of technology-based start-up firms in Indonesia is growing, and some Indonesian-based start-ups have achieved unicorn status with a valuation of at least USD 1 billion. Start-ups operate in an extreme highly dynamic environment. Giardino, Unterkalmsteiner, Paternoster, Gorschek and Abrahamsson (2014) found that most start-ups are highly reactive as they encounter a high level of uncertainty due to a rapidly evolving business environment. As new firms, start-ups also experience a high failure rate and most require funding from external sources (i.e., they are not financially self-sustaining). Their unique business context requires that start-up organizations be nimble and flexible.

To manage the constant changes of the business landscape, firms generally conduct their activities using a team-based (Van Knippenberg \& Mell, 2016) and projectized approach. Start-ups, which are typically characterized by rapid innovation (Nurcahyo, Akbar \& Gabriel, 2018) and highly reactive tactics (Giardino et al., 2014), have an even more compelling need for projectized and team-based strategies. Projects enable flexible, multidisciplinary initiatives (Mantel, Meredith, Shafer \& Sutton, 2008), examples of which include new product and software development projects (Unterkalmsteiner, Abrahamsson, Wang, Nguyen-Duc, Shah, Bajwa et al., 2016) that require team-level innovation and effective complex problem-solving.

Realizing the potential impact and efficacy of working in a team has become a recurring theme in general management studies. An important perspective when studying team effectiveness and performance is centered around principles of team diversity. In developed countries, diversity studies are conducted mainly in response to the rapidly increasing heterogeneity of workplaces. Organizations, and in effect working teams, are witnessing demographic changes with more women, minorities, and people from diverse specific backgrounds (Hunt, Layton \& Prince, 2015; van Veelen \& Ufkes, 2019; Williams \& O’Reilly, 1998).

Unique additional challenges are observable in start-up firms from the team performance perspective. Project teams working in start-ups are often characterized by their limited resources, including time and experience. Furthermore, employee mobility (Van Knippenberg \& Mell, 2016) and high turn-around within and across start-ups provide an extra layer of managerial complexity. Despite these extra challenges, there are few studies of project team diversity in the start-up context. A literature review of studies of entrepreneurial teams (another term used for start-up teams) and team cognition (part of the team composition/diversity concept) in first-tiered journals (1993-2013) by de Mol, Khapova and Elfring (2015), for instance, yielded a final entry of 44 relevant studies. A more specific review by Zhou and Rosini (2015) of research on start-ups and team diversity (1990 to 2013) resulted in just 31 empirical studies.

As described in the literature, studies of team diversity and performance have yielded conflicting results, despite the advancement of theoretical perspectives and empirical protocols. Moreover, most studies have been conducted within a non-start-up business environment, for which developed-country settings are emphasized. Results from past studies in developed countries are not easily transferable to new contexts and cultures. A study by Hunt et al. (2015), for instance, found variations by countries in terms of the diversity-performance associations. Roberson, Ryan and Ragins (2017) also argued that contexts matter in diversity studies, which in this case are both occupational (start-ups) and cultural (Indonesian). Accordingly, a new project team diversity study that emphasizes the specific context of start-up firms in a developing country with a unique culture has important significance.

The objectives of this study are twofold: (a) to establish a theoretical model that proposes the existence of an intricate relationship between project team diversity and performance. This model should consider recent conceptual and empirical developments in the field with a necessary adaptation to the specific context of Indonesian start-ups; (b) to empirically verify the model using Indonesian datasets.

This study has potential to offer both theoretical and practical contributions. From a theoretical perspective, it adopts recent theoretical principles of diversity by combining aspects of two competing research camps. As demonstrated in the following section, it also extends the theoretical framework by introducing an emerging diversity construct, i.e., ideological diversity. 
From a practical viewpoint, this study offers empirical insights on a unique setting, i.e., start-ups in a developing country (Indonesia). Indonesia offers an interesting case for diversity studies due to its unique cultural context. As an archipelago nation comprising more than 13,000 islands that are home to the world's fourth-largest population, Indonesia is a cultural melting pot with 15 major ethnic groups, 700+ traditional languages, and six official religions (CIA, 2019). Furthermore, Indonesia is currently experiencing an increasing degree of polarization in terms of ideological and political views (Tapsell, 2019). The recent democratic presidential election, for instance, was seen by many as the most divisive of all time, involving two competing political blocks, i.e., pluralists/nationalists and Islamists. This polarization is believed to have reverberated deeply throughout the Indonesian population (Aspinall, 2019). It is interesting to study whether this ideological/political polarization and its possible adverse impact have extended to the team/start-up setting.

\section{Evolving Nature of Diversity Studies}

Organizational diversity is an interesting topic of research due to its possible impact on performance (Wu, Zhao, Zuo \& Zillante, 2019; Zhou \& Rosini, 2015). At the specific level of team diversity and team performance, research has evolved significantly but the results are not conclusive, as indicated in the following section. Over time, the concept of diversity has also expanded from a single to multi-faceted constructs. Moreover, the proposed theoretical structure for this concept, which is based on a simple, direct "diversity and performance" association has now been extended and become more nuanced by the introduction of intervening and moderating variables, as discussed below.

\subsection{Conceptualization and Operationalization of Diversity}

The early concept of diversity was often reflected by a simple, single aspect pertaining to the demographic attributes of the team members. As such, a team was considered to be highly diverse when it comprised members with differing demographic features, such as race or gender. Subsequent advancement of this concept has involved the consideration of multiple classes of diversity. For instance, a $2 \times 2$ classification was utilized along two continuums_-"salience" and "job relatedness" (e.g., Roberson et al., 2017; Williams \& O'Reilly, 1998).

Scholars have also proposed a variety of approaches to diversity operationalization. For example, Chan (1998) proposed a typology of generic composition models that includes dispersion models. Harrison and Klein (2007) reviewed and further clarified this construct, then identified three distinct types of diversity, namely separation (polarization), variety (spread, categorical variability), and disparity (inequality). They further argued that different conceptualizations/definitions would lead to different measures and methods of statistical testing.

While diversity conceptualizations remain divergent, recent studies have identified common grounds, namely: (a) use of a compositional perspective, (b) an emphasis on within-group variations, and (c) highlighting the distribution of differences among team members (Roberson et al., 2017).

\subsection{Diversity-Performance Structuring}

Studies on the structure of the relationship between diversity and performance reflect the evolution of this body of knowledge. The majority of early diversity studies assumed a direct diversity-performance relationship, as summarized by Williams and O’Reilly (1998). As stated earlier, conflicting research perspectives and findings were evident.

There are two major and competing research camps pertaining to this field of study: (a) the social categorization/identification theory and (b) the information/decision-making theory. The social categorization theory (Tajfel, 1981) or social identification theory (Abrams \& Hogg, 1990, 2006) first established by demographic researchers assert in principle that diversity has detrimental effects on teams or organizational performance. They suggest that dissimilarity in the demographic composition of teams would increase conflict, reduce cohesion, and disrupt effective communication. The social theory explains this situation as follows. People have a strong motivation to maintain their self-esteem, thus, they create social comparisons by classifying themselves and others with respect to certain characteristics. In effect, they form a perceived, self-group, which is considered to be different from others in terms of age, race, status, religion, or other salient demographic attributes. A positive 
self-identity is usually created when members of one's own group are seen as being more attractive and those outside the group as less cooperative or trustworthy. These characteristics are often exaggerated by stereotyping, polarization, and anxiety toward other groups. This eventually results in low satisfaction, high turnover, low cohesiveness, communication breakdown, and conflict, all of which are self-fulfilling. Teams in these conditions will go downhill in terms of their collective performance.

The information/decision-making theory suggests there is positive value in diversity (Cox \& Blake, 1991). This theory asserts that team heterogeneity may offer: (a) new, unique perspectives; (b) complementary skills and abilities, and (c) more comprehensive outside networks, which may lead to improved team-level creativity and innovation and an enhanced ability to solve complex problems. Hence, the theory suggests that for certain tasks, more diverse teams could perform better.

Ensuing studies in diversity consider both camps to have theoretical and empirical merits. Accordingly, scholars often take a more reconciliatory approach by combining the principles of these two research camps. Such theoretical models suggest multiple paths for "diversity" and "performance" linkages. Team-level performance is then observed as a net effect of the combined results.

Recent studies have included more nuanced models that introduce moderating or mediating variables, as succinctly explained by Van Knippenberg and Schippers (2007). Some scholars introduce process-related variables, such as "conflict", as a possible mediator, e.g., (Pelled, 1996), while others include moderating variables such as task-related contexts, e.g., (Horwitz \& Horwitz, 2007; Williams \& O’Reilly, 1998)]. Despite theoretical refinement, mixed results are still observable. Bowers, Pharmer and Salas (2000) conducted a meta-analysis of 13 diversity studies and found the joint effect of diversity on "gender", "ability", and "personality" to be small and not statistically significant, yet their findings support the positive effect of diversity. Interestingly, the study also found that this effect is moderated by "task type" or "task difficulty". Another meta-analysis of 24 studies by Webber and Donahue (2001) found insufficient evidence for any linkage between diversity (job-relatedness), team cohesion, and team performance. The authors of the study, nevertheless, reported a possible moderating effect of "organizational context", "measurement", and "time". A more recent meta-analysis of team diversity research (1985-2006) performed by Horwitz and Horwitz (2007) addressed the role of various moderators on the diversity-performance linkage and found that task complexity and team type (i.e., work team, parallel team, project team) do not statistically moderate the diversity-performance association.

Roberson et al. (2017) argued that the persistent inconsistency of results could be attributed to variations in the conceptualization, operationalization, contexts, and performance measures. These authors also highlighted the idea that cultural dimensions (e.g., collectivism vs. individualism) could significantly contribute to diversity. Inconclusive results present an opportunity for follow-up studies, specifically in areas with different cultural backgrounds. Hence, the following research question must be specifically addressed: within the specific context of start-up firms in a developing nation (Indonesia), what effect does project team diversity have on conflict and project performance?

\section{Theoretical Model}

With respect to the theoretical model, two major paradigms on team diversity and performance were consulted. As described above in our review of the literature, the information and decision-making school of thought suggests a positive association, whereas the social classification research camp suggests a negative association between diversity and team performance. Following the study by Liang, Liu, Lin and Lin (2007), we found that different aspects of team diversity are relevant for one or the other research camp. Specifically, we assert that "work diversity" is more pertinent as a predictor within the decision-making paradigm, whereas "ideological diversity" is relevant to the social classification paradigm. Moreover, we conjecture that "social diversity" is linked to both paradigms. We introduce a new predictor-ideological diversity—to emphasize an emerging concept of diversity. This predictor replaces "value diversity", which was the term used in previous studies by Liang et al. (2007) and O’Reilly III, Chatman and Caldwell (1991).

In addition to the incorporation of these two competing perspectives, our proposed theoretical model includes a process-related mediating variable, [c.f. (Pelled, 1996)], namely "conflict". Theorists suggest there are multiple 
dimensions of "conflict" due to its broad application. As early as the 1950s, Pelled (1996) reported that scholars had distinguished two types of conflict, namely, task disagreement and interpersonal arguments. A study by Jehn (1994) which involved 440 respondents, also identified two factors.

Accordingly, by making the above distinction while acknowledging the dual-perspective realms, two aspects of "conflict" are included here: "task-related conflict" and "emotional conflict". As the name implies, task-related conflict is attributable to substantive disagreements among team members that pertain to work-related problems (e.g., perspectives, ideas, approaches, and possible solutions). Emotional conflict, in contrast, relates more to clashes of personality and other non-work-related determinants during interpersonal, non-productive incidents.

Figure 1 shows the proposed integrated model. Overall, we purport that the relationship between "diversity" and "team performance" is mediated by "conflict". Further, the following path is consistent with the information and decision-making paradigm: "work diversity" $\rightarrow$ "task-related conflict" $\rightarrow$ "performance". Meanwhile, along the social classification paradigm, the following path is identifiable: "ideological diversity" $\rightarrow$ "emotional conflict" $\rightarrow$ "performance". Details of these hypotheses are provided at the end of this section.

Our theoretical analysis initially considered the inclusion of possible moderating variables, i.e. task complexity and task type. These variables were eventually excluded from the final theoretical model to maintain model's parsimony. Regarding task complexity, studies on complexity in other project domains such as project risk (Hartono, 2018) and project leadership (Hartono, Sulistyo \& Umam, 2019) have found project complexity to affect the strength (i.e., weakness or strength) and sign (i.e., positive or negative) of the relationship between respective key predictors and project performance. Within project diversity research, however, this moderating effect seems to be negligible, as reported in a meta-analysis study by Horwitz and Horwitz (2007). Hence, "task complexity" was eventually excluded from our theoretical model.

Task type was another possible moderating variable, as suggested by Williams and O'Reilly (1998). However, this variable was dropped from subsequent analysis since its study focuses on start-up projects in which, in our opinion, there was less variation in terms of the types of project tasks. The post-survey analysis (see Table 4) confirmed our assumption of rather homogenous types of tasks/projects (e.g., marketing campaign, digital content production, platform update, product $R \& D$, web development). These projects can be viewed as typically requiring similar features of complex problem-solving and high levels of creativity. Their limited variation could render statistical analysis ineffective; hence this variable was also excluded.

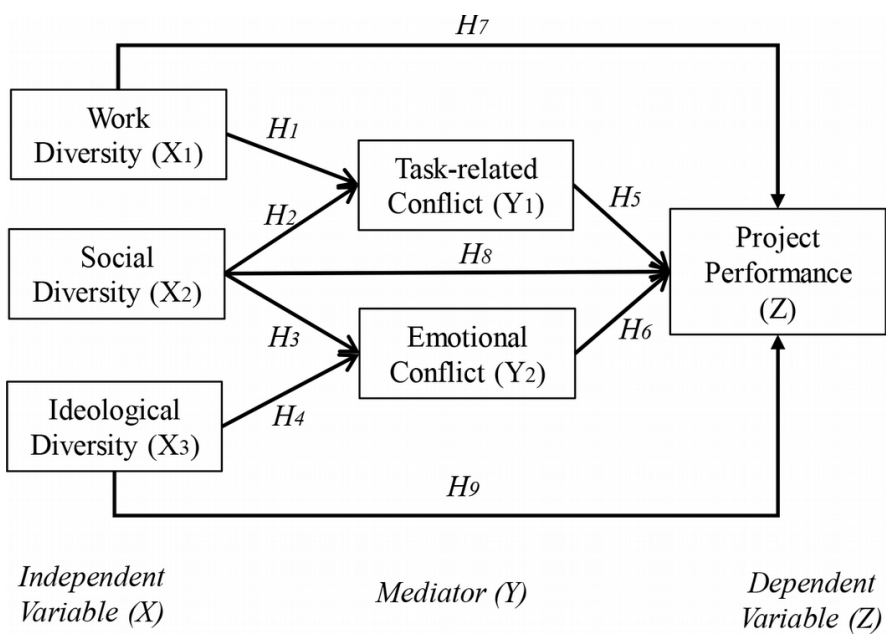

Figure 1. Proposed theoretical model

In the following section, we present our research hypotheses.

In a project environment, work diversity is considered to reflect differences among project team members with respect to work-related matters. Those include differences in educational background (e.g., engineering vs. 
business), knowledge, skills, and ability. Such differences may affect the way the team members perceive project tasks and problems. Furthermore, different and sometimes conflicting views with respect to concepts may emerge that could impact the approach and procedures used to perform tasks and offer solutions. Differing views and ideas may cause disagreement among team members, which in turn result in task-related conflict. Hence, the more diverse the team in terms of work-related attributes, the higher the task-related conflict within the team.

\section{$H_{1}$ : Work diversity positively influences task-related conflict.}

Studies suggest that "social diversity" could be positively linked to task conflict (Pelled, 1996). Social diversity is reflected by individual [demographic] attributes such as age and personal experience, gender, ethnicity, and religion. Within a project team setting, age and experience may be good predictors of how people perceive the world. Some studies have found a linkage between age and risk tolerance (Wang \& Hanna, 1997), whereby team members of different ages may have different attitudes toward risks. Furthermore, different generations (e.g., Baby boomers vs. Millennials) may have distinctive motivations (Queiri, Dwaikat \& Yusoff, 2014), preferences (e.g., (Philippe, 2013), and priorities in the workplace. Gender may also be a strong predictor of differences. Female employees, for instance, could offer unique perspectives in the development of product requirements. Similarly, ethnicity and religious affiliation could generate differing views (Hunt et al., 2015) that could lead to task-related conflicts. Hence:

\section{$\mathrm{H}_{2}$ : Social diversity positively influences task-related conflict.}

Interestingly, it is purported that the same "social diversity" that is reflected by age, gender, ethnicity, and religion may also be associated with non-task-related (i.e., emotional) conflict. In accordance with the social classification paradigm, team members may consider this to be an explicit/salient type of diversity in their project team and tend to self-categorize. As such, team members would unwittingly create a mindset of we vs. them, with those outside one's group being perceived as less attractive. The result would be negative stereotyping and polarization among team members, which would increase within-group anxiety, reduce satisfaction, and eventually result in personal or emotional conflict. Hence:

\section{$H_{3}:$ Social diversity positively influences emotional conflict.}

Ideological diversity is reflected by differences in inherent values such as humanism vs. faith-based, egalitarianism vs. tribalism, and diversity in values regarding sexual identity, freedom and civil liberties, and bodily rights. These values generate individual divisions along the liberal to conservative continuum. Like Hypothesis 2, ideological diversity may evoke social categorization, i.e., a mindset of us vs. them, which will leads to prejudice and stereotyping. As a result, personal or emotional conflict will arise within the team from this adverse condition. Hence:

\section{$\mathrm{H}_{4}$ : Ideological diversity positively influences emotional conflict.}

We argue that task-related disagreement has a positive effect on project performance. Task-related conflict offers a means of exploration of new concepts, ideas, methods, and procedures. Effective project exploration may result in creative deliberation and flexibility in multiple scenarios for potential solutions, which are especially important in start-up projects. Moreover, studies offer convincing evidence that exploration and flexibility are key success factors in addressing project uncertainty (Hartono, Sulistyo, Chai \& Indarti, 2019; Maylor \& Turner, 2017; Turner, Maylor \& Swart, 2015). In addition, task-related conflicts within start-ups may highlight unique perspectives that relate to the specific needs of new market segments. Hence:

\section{$H_{5}$ : Task-related conflict positively influences performance.}

We purport that personal or emotional conflict is detrimental to project performance. Emotional conflict may result in poor communication and coordination, higher turnover, and reduced cohesiveness among project team members. Such situations may result in poor project performance. Hence:

\section{$H_{6}$ : Emotional conflict negatively influences performance.}

To ensure completeness of the theoretical model and to evaluate possible mediating effects, we also conjecture that there is a direct relationship between respective aspects of diversity and project performance. 
Hence:

$H_{7}$ : Work diversity positively influences performance.

$H_{8}$ : Social diversity negatively influences performance.

$H_{9}$ : Ideological diversity negatively influences performance.

\section{Measures}

\subsection{Diversity}

In this study, diversity was conceptualized as a project team-level measure (Roberson et al., 2017) that reflects the composition of certain attributes of its members. It denotes a level of heterogeneity/dissimilarity of within-group characteristics, as represented by either variety or separation (Harrison \& Klein, 2007).

Three types of diversity are identified and, for the purposes of this study, were selected independent variables, namely "work diversity", "social diversity", and "ideological diversity". Following the typology of Harrison and Klein (2007), "work" and "social" diversity are operationalized as the level of variety of specific attributes among project team members and ideological diversity is the level of separation among team members with respect to ideology.

To quantify the values of team-level diversity, we utilized a dispersion composition model (Chan, 1998) that combines lower-level datasets of team members to calculate the corresponding team-level diversity. As such, the within-group variations of individual responses are treated as measurable focal points for calculating diversity. Accordingly, individual team members performed a self-assessment by answering questionnaire items/indicators pertaining to attributes for these three diversity aspects. Indicators of "work diversity" were mostly adopted and translated into Bahasa Indonesia from previous works by Jehn, Northcraft and Neale (1999); Pelled (1996). Items relating to "social diversity" were taken from works by Liang et al. (2007) and Jehn et al. (1999), and items related to "ideological diversity" were taken from (Everett, 2013; Heywood, 2004; Ramseyer \& Rasmusen, 2015). Team-level diversity scores were then derived by aggregating the scores of all team members in the respective project teams.

Consistent with the proposed conceptualization described above, ideological diversity, which employs a separation perspective and an interval data type, is represented here by the population standard deviation (SD) of the individual responses within respective teams, as determined using Equation (1). Work and social diversity reflect the degree of attribute variation of members within the team (variety type), which are mostly measured based on categorical data. Accordingly, in the aggregation process of this study we employed the Shannon Diversity Index (SDI) (Teachman, 1980), which is indicated by Equation (2). This index measures the distribution of team members among the possible categories of a variable.

$$
\begin{aligned}
& S D=\sqrt{\left[\frac{\sum\left(S_{i}-S_{\text {mean }}\right)^{2}}{n}\right\rceil} \\
& S D I=\sum_{i=1}^{i} P_{i}\left(\ln P_{i}\right)
\end{aligned}
$$

Note:

$\mathrm{SD}$ : (population) standard deviation;

$\mathrm{S}_{\mathrm{i}} \quad$ : attribute value for individual team member $\mathrm{i}$;

$S_{\text {mean }}$ : team-level mean for attribute value;

$\mathrm{n} \quad$ : the number of team members.

SDI : Shannon Diversity Index;

Pi: $\quad$ : the fraction of team members which falls into category $i$.

\subsection{Conflict}

"Conflict" as a mediating variable is related to the degree of intellectual/emotional disagreement and tension among project team members, as perceived by the respective team members. Two types of conflict (task-related 
and personal/emotional) were included in the analysis. Individual team members were queried by means of a self-evaluation survey regarding the two conflict types. Items on the questionnaire were adopted from previous works by Jehn (1995) and Guetzkow and Gyr (1954). Again, aggregation was performed to compute a single, team-level, itemized data point from the datasets of individual team members. For conflict-related scores, average values were employed.

\subsection{Performance}

Due to the broad nature of the concept of "project performance", in this study, we included three well-recognized indicators (Nidumolu, 1995; Pinto \& Slevin, 1988; PMI, 2017), namely: (a) performance with respect to the management of the project, (b) performance in terms of meeting the clients' requirements and expectations, and (c) performance pertaining to the opportunity of the team members to learn from the project. Individual members were queried for their opinions and individual itemized scores were then averaged to the team level.

Ideally, client-related performance indicators $\left(\mathrm{Z}_{2}\right)$ are drawn directly from project clients. However, we experienced practical problems in the identification of such respondents during the study, let alone inquiring about their perspectives. Accordingly, we depended upon the subjective view of the project team to consider the benefits of the project deliverables to their clients. Since most start-up projects involve small teams and adopt fairly informal approaches, team members seem to have equal opportunity and frequency to engage with clients, which means that all members could have valid opinions pertaining to clients. Accordingly, we utilized aggregated data from all team members of a particular project to measure the client-focused performance. This multiple-factor client-related performance measure may also reduce the degree of bias.

Table 1 lists the variable types, operational definitions, compositional measures, number of indicators, and references for key variables. A formative variable, such as "work diversity", indicates that the variable was formed or constructed by the sum of its elements, i.e., in this case, the three questionnaire indicators. A reflective variable such as "project performance" suggests that the overall value would be consistently reflected by all its components (indicators). Appendix A presents the variable-indicator matrix.

\section{Research Method}

We utilized a two-stage quantitative approach in which the first stage emphasized theoretical model development, as reported in the preceding chapter. The second stage focused on the empirical work, which was performed by means of a self-reported, cross-sectional survey. The subsequent testing of hypotheses by PLS was performed the using smartPLS software program developed by Ringle, Wende and Becker (2015).

For the survey study, the target population comprised project teams of Indonesian start-up firms. The unit of analysis was the project team, with possibly more than one project for each firm. Due to the difficulty in obtaining a sample frame, convenience sampling was used. The nature of this study also required responses from multiple respondents for respective single datasets. Hence, a personal approach was used. That is, for respective targeted firms, we contacted representatives of the firms to request their participation. When agreed upon, a follow-up discussion was conducted to determine which project(s) would be chosen and to identify team members as potential respondents. Ideally, all team members would be queried, but only three to six members of the respective teams responded to the request to complete the questionnaire.

Responses from individual team members were collected either directly (face-to-face) or online. Out of the 118 start-up firms contacted, 68 responded positively, thereby yielding a 57.6\% response rate. As depicted in Table 2, 102 project teams participated in the survey and since multiple team members were queried regarding their respective teams, overall, 395 respondents provided usable individual datasets.

Prior to initiating the main study, a survey instrument was developed that included the indicators creation/adoption, two-way translation from English to Bahasa Indonesia, and inclusion of additional information such as the demographics of the respondents and firms as well as project-related information. The original instrument draft was then qualitatively evaluated for face validity. The instrument package comprised the final version of the instrument and a cover letter. 


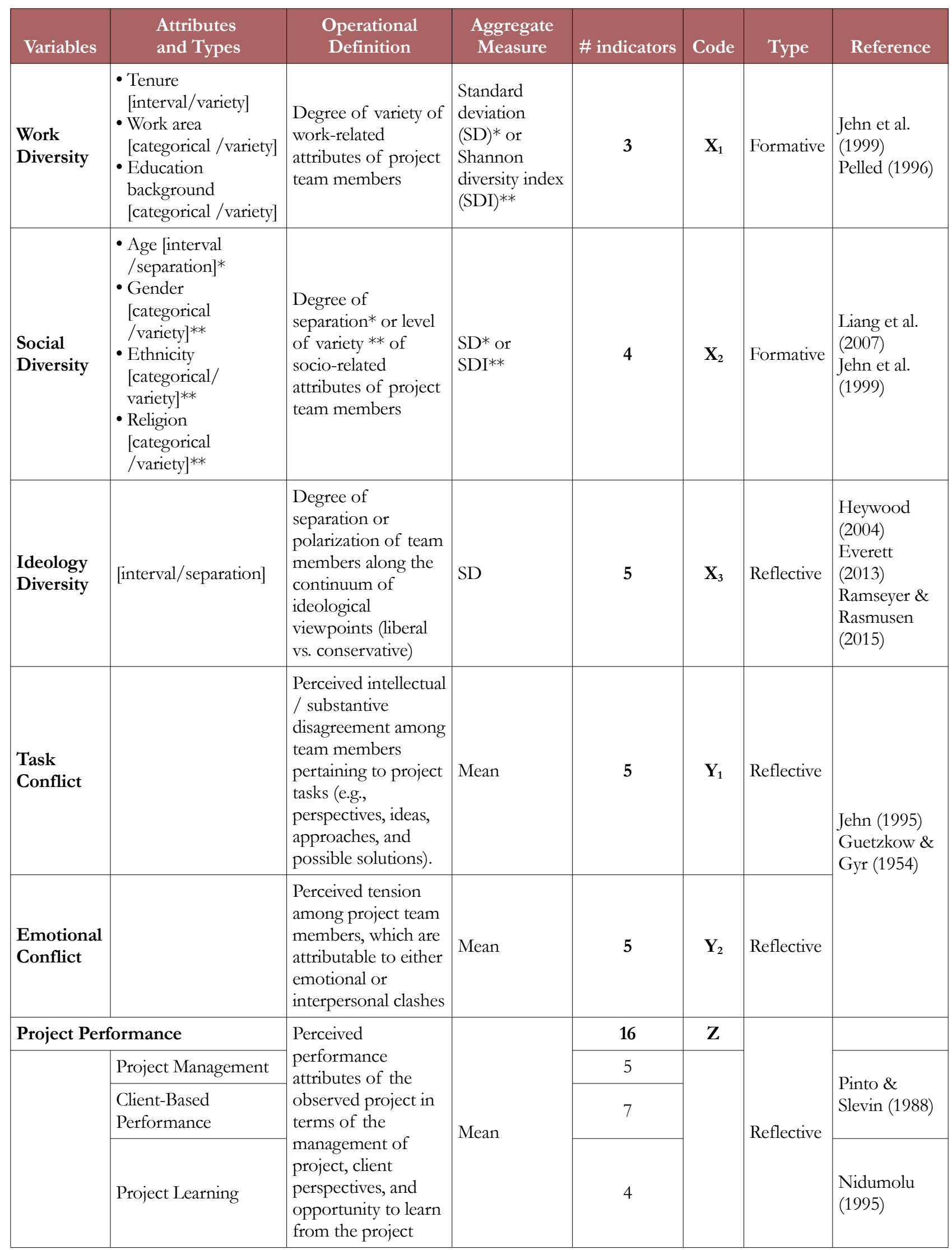

Note: $*$ for tenure, age indicators; ${ }^{* *}$ for gender, ethnicity, religion indicators

Table 1. Variables, Attributes, and Operational Definitions 


\begin{tabular}{|l|r|r|}
\hline \multicolumn{2}{|c|}{ Sources } & \multicolumn{2}{c|}{ Out } \\
\hline Number of firms & 12 & 12 \\
\hline Direct & 106 & 56 \\
\hline E-mail / similar channels & 118 & 68 \\
\hline Total & & $57.6 \%$ \\
\hline Response rate & & 102 \\
\hline Number of project teams $(=\mathrm{n})$ & & 395 \\
\hline Number of respondents & & \\
\hline
\end{tabular}

Table 2. Response Rate

\section{Results and Discussion}

\subsection{Demographic Data}

Table 3 presents the demographics of the individual respondents. Male respondents (68\%) predominated the participant data and the academic backgrounds were diverse, including engineering (industrial, electrical), information technology and computer science, business and management, and psychology. Moreover, the clusters of job types revealed differences in the nature of work, including multimedia production, front-end development, and software engineering.

An interesting fact with respect to the ethnicity of the respondents is that at least eleven (11) distinct ethnicities are represented in this study. A high variation was also found for religion, which included the five official religions in Indonesia as well as atheism/agnosticism. In terms of age, the respondents were relatively young, which is typical of start-ups (Ouimet \& Zarutskie, 2014).

Table 4 lists the project types observed in this study, which primarily require creative processes, including marketing campaigns, digital content creation, and product research and development.

Table 5 lists the locations of the firms' urban head offices. The reported locations include some of the largest cities in Indonesia. Yogyakarta is at the top of the list (around 31\%), which is a base for researchers and provides ease of access. Jakarta, the capital city, is in second place, accounting for 18 firms $(26 \%)$.

\subsection{Testing the Hypotheses}

The statistical analysis method we used to test our hypotheses was the partial least squares (PLS) method. PLS, a variate-based structural equation model (Wong, 2013), was chosen because it is considered to provide a good approximation of the more advanced covariate-based structural equation modeling used in quantitative studies. PLS has the following features (Hair, Ringle \& Sarstedt, 2011): (a) ability to accommodate rather complex structural models, (b) a limited sample size is acceptable, (c) certain violations of the assumptions are tolerable, and (d) formative variables are included. This study fits the above characteristics.

Prior to the analysis, we calculated the required sample size. With reference to a suggestion by Marcoulides and Saunders (2006), the minimum sample size of the study (with a maximum number of arrows pointing at a latent variable $=5$ ) is 70. Another recommendation by Hair et al. (2011) is that the sample size should either be: (1) ten times the largest number of formative indicators used to compute a single latent variable (in this study: $10 \times 4=40$ ), or (2) ten times the largest number of structural paths directed at a particular latent variable $(10 \times 5=50)$. Since this study utilized 102 datasets, we assert that the sample size is sufficient for PLS analysis.

Using PLS, we performed two steps in the key statistical analysis: (a) evaluation of the validity and reliability of the instrument, i.e., outer model analysis, and (b) empirical tests of the theoretical model, i.e., inner model analysis. Figure 2 shows the structural model developed for the PLS platform, which reflects our hypotheses. As we can see in the figure, consistent with the previously described variable conceptualization and operationalization, items/indicators are defined in the model as either being formative (i.e., work diversity, social diversity) or reflective (i.e. ideological diversity, task conflict, emotional conflict, and project performance). 


\begin{tabular}{|l|r|r|}
\hline \multicolumn{1}{|c|}{ Gender } & \multicolumn{1}{c|}{ Count } & \multicolumn{1}{c|}{ Percentage } \\
\hline Male & 269 & $68.10 \%$ \\
\hline Female & 126 & $31.90 \%$ \\
\hline Total & $\mathbf{3 9 5}$ & $\mathbf{1 0 0 . 0 0 \%}$ \\
\hline
\end{tabular}

\begin{tabular}{|l|r|r|}
\hline \multicolumn{1}{|c|}{ Cluster of Job Type } & \multicolumn{1}{c|}{ Count } & \multicolumn{1}{c|}{ Percentage } \\
\hline Multimedia Production & 101 & $25.57 \%$ \\
\hline Front-end Development & 66 & $16.71 \%$ \\
\hline Software Engineering & 61 & $15.44 \%$ \\
\hline Other Fields & 51 & $12.91 \%$ \\
\hline Marketing & 34 & $8.61 \%$ \\
\hline Business Analysis & 25 & $6.33 \%$ \\
\hline User Experience & 24 & $6.08 \%$ \\
\hline Backend Development & 18 & $4.56 \%$ \\
\hline Event Management & 15 & $3.80 \%$ \\
\hline Total & $\mathbf{3 9 5}$ & $\mathbf{1 0 0 . 0 0 \%}$ \\
\hline
\end{tabular}

\begin{tabular}{|l|r|r|}
\hline \multicolumn{1}{|c|}{ Academic Background } & \multicolumn{1}{c|}{ Count } & \multicolumn{1}{c|}{ Percentage } \\
\hline Industrial Engineering & 59 & $14.94 \%$ \\
\hline Other Fields & 57 & $14.43 \%$ \\
\hline Information \& Technology & 52 & $13.16 \%$ \\
\hline Computer Science & 44 & $11.14 \%$ \\
\hline Business \& Management & 41 & $10.38 \%$ \\
\hline Communication Studies & 34 & $8.61 \%$ \\
\hline Urban Planning & 22 & $5.57 \%$ \\
\hline Electrical Engineering & 15 & $3.80 \%$ \\
\hline Agriculture-Related & 15 & $3.80 \%$ \\
\hline Fine Arts & 13 & $3.29 \%$ \\
\hline Electronics \& Instr. & 13 & $3.29 \%$ \\
\hline Visual \& Graphic Design & 11 & $2.78 \%$ \\
\hline Programming Course & 10 & $2.53 \%$ \\
\hline Psychology & 9 & $2.28 \%$ \\
\hline Total & $\mathbf{3 9 5}$ & $\mathbf{1 0 0 . 0 0 \%}$ \\
\hline
\end{tabular}

\begin{tabular}{|l|r|r|}
\hline \multicolumn{1}{|c|}{ Ethnicity } & \multicolumn{1}{c|}{ Count } & \multicolumn{1}{c|}{ Percentage } \\
\hline Javanese & 187 & $47.34 \%$ \\
\hline Sundanese & 59 & $14.94 \%$ \\
\hline Chinese & 34 & $8.61 \%$ \\
\hline Batak & 27 & $6.84 \%$ \\
\hline Betawi & 25 & $6.33 \%$ \\
\hline Balinese & 18 & $4.56 \%$ \\
\hline Minang & 17 & $4.30 \%$ \\
\hline Bugis & 15 & $3.80 \%$ \\
\hline Madura & 6 & $1.52 \%$ \\
\hline Papuan & 4 & $1.01 \%$ \\
\hline Malay & 3 & $0.76 \%$ \\
\hline Total & $\mathbf{3 9 5}$ & $\mathbf{1 0 0 . 0 0} \%$ \\
\hline
\end{tabular}

\begin{tabular}{|l|r|r|}
\hline \multicolumn{1}{|c|}{ Religion } & \multicolumn{1}{c|}{ Count } & \multicolumn{1}{c|}{ Percentage } \\
\hline Islam & 253 & $64.05 \%$ \\
\hline Catholic & 57 & $14.43 \%$ \\
\hline Christian & 33 & $8.35 \%$ \\
\hline Atheism/Agnosticism & 31 & $7.85 \%$ \\
\hline Hindu & 14 & $3.54 \%$ \\
\hline Buddha & 7 & $1.77 \%$ \\
\hline Total & $\mathbf{3 9 5}$ & $\mathbf{1 0 0 . 0 0 \%}$ \\
\hline
\end{tabular}

\begin{tabular}{|l|r|}
\hline \multicolumn{1}{|c|}{ Age } & \multicolumn{2}{|c|}{ Value } \\
\hline Median & 23 \\
\hline Min/max & $20 / 28$ \\
\hline Standard Deviation & 1.54 \\
\hline
\end{tabular}

Table 3. Profile of Respondents

\begin{tabular}{|c|l|r|r|}
\hline & \multicolumn{1}{|c|}{ Project Type } & \multicolumn{1}{c|}{ Frequency } & \multicolumn{1}{c|}{ Percentage } \\
\hline 1 & Marketing campaign & 25 & $24.5 \%$ \\
\hline 2 & Digital content production & 21 & $20.6 \%$ \\
\hline 3 & Platform update \& maintenance & 17 & $16.7 \%$ \\
\hline 4 & Product R\&D & 15 & $14.7 \%$ \\
\hline 5 & Web development & 10 & $9.8 \%$ \\
\hline 6 & New feature rollout & 2 & $7.8 \%$ \\
\hline 7 & Brand design & 4 & $2.0 \%$ \\
\hline 8 & Other client-related projects & $\mathbf{1 0 2}$ & $3.9 \%$ \\
\hline & Total & & $\mathbf{1 0 0} \%$ \\
\hline
\end{tabular}

Table 4. Types of Projects 


\begin{tabular}{|l|r|r|r|r|}
\hline Location & Total Start-ups & Percentage & \multicolumn{1}{l|}{ Total Teams } & \multicolumn{1}{l|}{ Percentage } \\
\hline Yogyakarta & 21 & $30.88 \%$ & 47 & $46.08 \%$ \\
\hline Jakarta & 18 & $26.47 \%$ & 21 & $20.59 \%$ \\
\hline Bandung & 13 & $19.11 \%$ & 13 & $12.75 \%$ \\
\hline Surabaya & 8 & $11.76 \%$ & 8 & $7.84 \%$ \\
\hline Denpasar/Bali & 6 & $8.82 \%$ & 6 & $5.88 \%$ \\
\hline Makassar & 2 & $2.94 \%$ & 5 & $4.90 \%$ \\
\hline Medan & 2 & $2.94 \%$ & 2 & $1.96 \%$ \\
\hline Total & $\mathbf{6 8}$ & $\mathbf{1 0 0} \%$ & $\mathbf{1 0 2}$ & $\mathbf{1 0 0} \%$ \\
\hline
\end{tabular}

Table 5. Head Offices of Start-up Firms

The model coefficients and other model parameters were then estimated by running the SmartPLS program with the following conditions: (a) the value of the outer weight was initially set uniformly to 1 (as suggested by (Henseler, 2010); (b) the maximum number of iterations was 300 (as per (Ringle, Wende \& Will, 2005); and (c) the type of bootstrapping was basic with bias-corrected and accelerated bootstrap.

Figure 2 reveals interesting findings. The numbers in the circles reflect the coefficients of determination $\left(\mathrm{R}^{2}\right)$ of the variables, and the numbers on the arrows indicate path coefficients. As we can see in the figure, around $16.2 \%$ of the variance of "task conflict" is explained by "work diversity" and "social diversity", but only $11.1 \%$ of the variance of "emotional conflict" is explainable by both "social" and "ideological" diversity. Moreover, "project performance" has a rather high $\mathrm{R}^{2}$ score of $25.4 \%$, based on all three diversity variables and two conflict variables conflict.

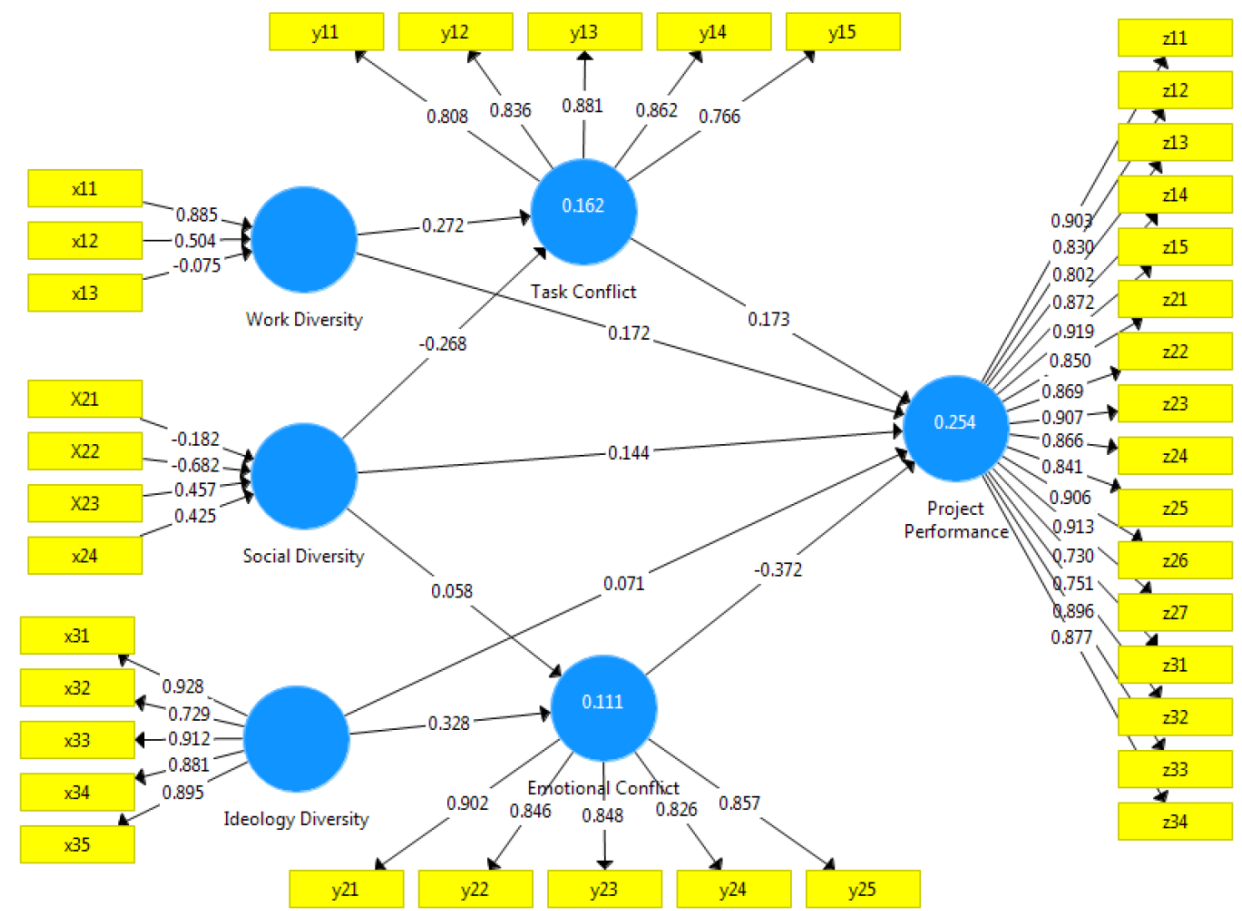

Figure 2. Structural Model from PLS Analysis

\subsubsection{Outer Model Test}

To evaluate the validity and reliability of the indicators and variables, we performed an outer model test. For the reflective indicators, we examined the outer models' loadings and significance, indicator reliability, composite reliability, and convergent and discriminant validity. For the formative variables, we performed outer model weight and significance and multicollinearity tests. 


\subsubsection{Evaluation of Reflective Indicators}

Table 6 shows the outer loadings, t-statistics, p-values, computed indicator reliability (the square of outer loadings), composite reliability, and average variance extracted (AVE). As can be seen, for all the observed reflective indicators, high and statistically significant (outer) loadings for the respective variables were obtained, with values greater than 0.7 (Hulland, 1999).

\begin{tabular}{|c|c|c|c|c|c|c|c|}
\hline $\begin{array}{l}\text { Latent } \\
\text { Variable }\end{array}$ & Indicators & Loadings & t statistics & p-values & $\begin{array}{l}\text { Indicator Reliability } \\
\left.\text { (Loadings }{ }^{2}\right)\end{array}$ & $\begin{array}{l}\text { Composite } \\
\text { Reliability }\end{array}$ & AVE \\
\hline \multirow{5}{*}{$\begin{array}{l}\text { Ideology } \\
\text { diversity }\end{array}$} & x31 & 0.928 & 45.844 & 0.000 & 0.861 & \multirow{5}{*}{0.940} & \multirow{5}{*}{0.760} \\
\hline & x32 & 0.729 & 11.645 & 0.000 & 0.531 & & \\
\hline & x33 & 0.912 & 44.344 & 0.000 & 0.832 & & \\
\hline & x34 & 0.881 & 28.206 & 0.000 & 0.776 & & \\
\hline & x35 & 0.895 & 32.799 & 0.000 & 0.801 & & \\
\hline \multirow{5}{*}{ Task conflict } & y11 & 0.808 & 22.263 & 0.000 & 0.653 & \multirow{5}{*}{0.918} & \multirow{5}{*}{0.692} \\
\hline & y12 & 0.836 & 20.701 & 0.000 & 0.699 & & \\
\hline & y13 & 0.881 & 32.754 & 0.000 & 0.776 & & \\
\hline & y14 & 0.862 & 32.500 & 0.000 & 0.743 & & \\
\hline & y15 & 0.766 & 14.633 & 0.000 & 0.587 & & \\
\hline \multirow{5}{*}{$\begin{array}{l}\text { Emotional } \\
\text { conflict }\end{array}$} & $\mathrm{y} 21$ & 0.902 & 49.912 & 0.000 & 0.814 & \multirow{5}{*}{0.932} & \multirow{5}{*}{0.733} \\
\hline & $\mathrm{y} 22$ & 0.846 & 22.508 & 0.000 & 0.716 & & \\
\hline & $\mathrm{y} 23$ & 0.848 & 25.822 & 0.000 & 0.719 & & \\
\hline & y24 & 0.826 & 21.992 & 0.000 & 0.682 & & \\
\hline & $\mathrm{y} 25$ & 0.857 & 28.882 & 0.000 & 0.734 & & \\
\hline \multirow{16}{*}{$\begin{array}{l}\text { Project } \\
\text { performance }\end{array}$} & z11 & 0.903 & 60.532 & 0.000 & 0.815 & \multirow{16}{*}{0.978} & \multirow{16}{*}{0.740} \\
\hline & z12 & 0.830 & 20.195 & 0.000 & 0.689 & & \\
\hline & z13 & 0.802 & 26.016 & 0.000 & 0.643 & & \\
\hline & z14 & 0.872 & 45.407 & 0.000 & 0.760 & & \\
\hline & z15 & 0.919 & 65.285 & 0.000 & 0.845 & & \\
\hline & z21 & 0.850 & 37.313 & 0.000 & 0.723 & & \\
\hline & z22 & 0.869 & 42.441 & 0.000 & 0.755 & & \\
\hline & z23 & 0.907 & 49.719 & 0.000 & 0.823 & & \\
\hline & z24 & 0.866 & 32.539 & 0.000 & 0.750 & & \\
\hline & $\mathrm{z} 25$ & 0.841 & 26.562 & 0.000 & 0.707 & & \\
\hline & z26 & 0.906 & 60.947 & 0.000 & 0.821 & & \\
\hline & z27 & 0.913 & 61.402 & 0.000 & 0.834 & & \\
\hline & z31 & 0.730 & 14.370 & 0.000 & 0.533 & & \\
\hline & z32 & 0.751 & 16.615 & 0.000 & 0.564 & & \\
\hline & z33 & 0.896 & 47.750 & 0.000 & 0.803 & & \\
\hline & z34 & 0.877 & 36.367 & 0.000 & 0.769 & & \\
\hline
\end{tabular}

Table 6. Summary of Results for Outer Models (Reflective Variables) 
The indicator reliability values are also an encouraging result. Twenty-two out of 31 indicators obtained an indicator reliability value higher than 0.7, the preferable threshold reported by (Hulland, 1999). The remaining indicators show reliability scores greater than 0.5. In addition, the internal consistency reliability values (or composite reliability) of the respective variables are 0.889 or higher, which are better than the 0.7 threshold (Bagozzi \& Yi, 1988). This and the previous reliability result suggest that, overall, the indicators of reflective variables have a high degree of consistency.

To evaluate the convergent validity, the average variance extracted (AVE) values obtained were 0.692 or higher, i.e., higher than the recommended 0.5 (Bagozzi \& Yi, 1988). Thus, the reflective variables can be interpreted as having good convergent validity.

To examine the discriminant validity, we followed the protocol reported by Fornell and Larcker (1981), the results of which are reported in Table 7. As can be seen, the cross-loading values of the respective variables (presented in diagonal cells, $>0.8$ ) are greater than the correlations among variables, which suggests good discriminant validity for the reflective variables.

The indicator loading values for the respective variables (not reported here) were found to have good discriminant validity, as indicated by higher indicator loading values within the respective constructs (intra-loadings) as compared to those of the across constructs (i.e. cross-loadings) (Hair et al., 2011). From the above evaluation results, it can be said that the reflective indicators and variables have good reliability and validity.

\begin{tabular}{|l|r|r|r|r|}
\hline & $\begin{array}{c}\text { Emotional } \\
\text { Conflict }\end{array}$ & $\begin{array}{c}\text { Ideology } \\
\text { Diversity }\end{array}$ & $\begin{array}{c}\text { Project } \\
\text { Performance }\end{array}$ & $\begin{array}{c}\text { Task } \\
\text { Conflict }\end{array}$ \\
\hline Emotional Conflict & $\mathbf{0 . 8 5 6}$ & & & \\
\hline Ideology Diversity & 0.328 & $\mathbf{0 . 8 7 2}$ & & \\
\hline Project Performance & -0.425 & -0.096 & $\mathbf{0 . 8 6 0}$ & \\
\hline Task Conflict & -0.421 & -0.191 & 0.325 & $\mathbf{0 . 8 3 2}$ \\
\hline
\end{tabular}

Table 7. Discriminant Validity for Reflective Variables

\subsubsection{Evaluation for formative indicators}

For the formative indicators, we evaluated the following: (a) outer model weight and significance and (b) multicollinearity. The outer weight represents the relative contribution of the respective indicators to their corresponding latent variables. Table 8 shows a statistically significant weight for $\mathrm{X}_{11}$ with respect to work diversity. We retained the other indicators because of their theoretical significance (Garson, 2016).

\begin{tabular}{|c|r|r|r|r|r|}
\hline & $\begin{array}{c}\text { Original } \\
\text { Sample (O) }\end{array}$ & $\begin{array}{c}\text { Sample } \\
\text { Mean (M) }\end{array}$ & $\begin{array}{c}\text { Standard } \\
\text { Deviation } \\
\text { (STDEV) }\end{array}$ & $\begin{array}{c}\text { t-statistics } \\
(\mid \text { O/STDEV |) }\end{array}$ & p-values \\
\hline $\mathrm{x} 11 \rightarrow$ Work Diversity & 0.885 & 0.779 & 0.233 & 3.789 & $\mathbf{0 . 0 0 0}$ \\
\hline $\mathrm{x} 12 \rightarrow$ Work Diversity & 0.504 & 0.430 & 0.343 & 1.470 & 0.142 \\
\hline $\mathrm{x} 13 \rightarrow$ Work Diversity & -0.075 & -0.020 & 0.276 & 0.273 & 0.785 \\
\hline $\mathrm{x} 21 \rightarrow$ Social Diversity & -0.182 & 0.159 & 0.382 & 0.476 & 0.634 \\
\hline $\mathrm{x} 22 \rightarrow$ Social Diversity & -0.682 & 0.026 & 0.610 & 1.118 & 0.264 \\
\hline $\mathrm{x} 23 \rightarrow$ Social Diversity & 0.457 & 0.182 & 0.453 & 1.008 & 0.313 \\
\hline $\mathrm{x} 24 \rightarrow$ Social Diversity & 0.425 & 0.095 & 0.442 & 0.962 & 0.336 \\
\hline
\end{tabular}

Table 8. Outer Weight for Formative Indicators 
Multicollinearity was examined using the variance inflation factor (VIF) shown in Table 9. A multicollinearity is said to exist if VIF $>5$ (Hair, Black, Babin, Anderson \& Tatham, 2006). We found no evidence of multicollinearity for the two reflective indicators.

\begin{tabular}{|c|r|r|}
\hline Variable & \multicolumn{1}{|c|}{ Indicator } & \multicolumn{1}{|c|}{ VIF } \\
\hline \multirow{3}{*}{ Work Diversity } & $\mathrm{x} 11$ & 1.002 \\
\cline { 2 - 3 } & $\mathrm{x} 12$ & 1.029 \\
\cline { 2 - 3 } & $\mathrm{x} 13$ & 1.030 \\
\hline \multirow{3}{*}{ Social Diversity } & $\mathrm{x} 21$ & 1.015 \\
\cline { 2 - 3 } & $\mathrm{x} 22$ & 1.035 \\
\cline { 2 - 3 } & $\mathrm{x} 23$ & 1.051 \\
\cline { 2 - 3 } & $\mathrm{x} 24$ & 1.039 \\
\hline
\end{tabular}

Table 9. Multicollinearity Test for Formative Indicators

\subsubsection{Inner Model Test: Total Effect}

Next, we performed an inner model test to evaluate the structure of the theoretical model and to test our hypotheses. The first analysis examined the total effect of the overall model, as presented in Figure 2. A bootstrap path analysis was performed of the latent variables. As shown in Table 10, three of the nine individual hypotheses yielded a statistically significant association. For $\mathrm{H}_{1}$, a positive linkage was observed between "work diversity" and "task conflict". For $\mathrm{H}_{4}$, a negative association was evident between "ideological diversity" and "emotional conflict". Another positive relationship was identified between "emotional conflict" and "project performance" $\left(\mathrm{H}_{6}\right)$. Hence, from the individual path analysis perspective, the following hypotheses are supported: $\mathrm{H}_{1}, \mathrm{H}_{4}$, and $\mathrm{H}_{6}$. In contrast, no compelling empirical evidence was obtained for $\mathrm{H}_{2}, \mathrm{H}_{3}, \mathrm{H}_{5}, \mathrm{H}_{7}, \mathrm{H}_{8}$, or $\mathrm{H}_{9}$.

\begin{tabular}{|c|c|c|c|c|c|}
\hline & $\begin{array}{c}\text { Original } \\
\text { Sample }(\mathrm{O})\end{array}$ & $\begin{array}{c}\text { Sample } \\
\text { Mean (M) }\end{array}$ & $\begin{array}{l}\text { Standard } \\
\text { Deviation } \\
\text { (STDEV) }\end{array}$ & $\begin{array}{c}\text { t-statistics } \\
(|\mathrm{O} / \mathrm{STDEV}|)\end{array}$ & p-values \\
\hline H1: Work Diversity $\rightarrow$ Task Conflict & 0.272 & 0.282 & 0.106 & 2.552 & $0.011^{*}$ \\
\hline H2: Social Diversity $\rightarrow$ Task Conflict & -0.268 & -0.037 & 0.304 & 0.882 & 0.378 \\
\hline H3: Social Diversity $\rightarrow$ Emotional Conflict & 0.058 & -0.038 & 0.167 & 0.347 & 0.729 \\
\hline H4: Ideology Diversity $\rightarrow$ Emotional Conflict & 0.328 & 0.335 & 0.093 & 3.528 & $0.000^{* *}$ \\
\hline H5: Task Conflict $\rightarrow$ Project Performance & 0.173 & 0.167 & 0.106 & 1.633 & 0.103 \\
\hline H6: Emotional Conflict $\rightarrow$ Project Performance & -0.372 & -0.377 & 0.099 & 3.751 & $0.000^{* *}$ \\
\hline H7: Work Diversity $\rightarrow$ Project Performance & 0.172 & 0.166 & 0.131 & 1.314 & 0.189 \\
\hline H8: Social Diversity $\rightarrow$ Project Performance & 0.144 & 0.008 & 0.180 & 0.798 & 0.425 \\
\hline H9: Ideology Diversity $\rightarrow$ Project Performance & 0.071 & 0.070 & 0.086 & 0.822 & 0.411 \\
\hline
\end{tabular}

Note: $* *$ significant at $\alpha=0.01 ; *$ significant at $\alpha=0.05$

Table 10. Inner Model Path Analysis (Total Effect)

\subsubsection{Inner Model Test: Mediating Effect}

We also examined the possible mediating effect of "conflict" for the association of "diversity" and "performance". To do so, we performed a two-stage analysis by examining: (a) the total indirect effect (Table 11) and (b) the specific indirect effect (Table 12).

The total indirect effect was determined by the sum of all relevant effects from diversity to conflict to performance. For each path, the relevant effect is the multiplication of the effect value on "diversity conflict" and "conflict 
performance". As can be seen in Table 11, a statistically significant association ( $\mathrm{p}$-value $=0.010$ ) was identified only for "ideological diversity" and "performance".

To determine the specific direct effect of specific paths, we multiplied the individual effects. Table 12 lists the statistically significant relationship between "ideological diversity" and "emotional conflict" with respect to "project performance". Based on the results of the two-stage analysis, we can assert that "emotional conflict" was a full mediator between "ideological diversity" and "project performance".

\begin{tabular}{|c|c|c|c|c|c|}
\hline & $\begin{array}{c}\text { Original } \\
\text { Sample }(\mathrm{O})\end{array}$ & $\begin{array}{c}\text { Sample } \\
\text { Mean (M) }\end{array}$ & $\begin{array}{l}\text { Standard } \\
\text { Deviation } \\
\text { (STDEV) }\end{array}$ & $\begin{array}{c}\text { t-statistics } \\
(|\mathrm{O} / \mathrm{STDEV}|)\end{array}$ & p-values \\
\hline Work Diversity $\rightarrow$ Project Performance & 0.047 & 0.047 & 0.037 & 1.275 & 0.203 \\
\hline Social Diversity $\rightarrow$ Project Performance & -0.068 & 0.008 & 0.107 & 0.634 & 0.526 \\
\hline Ideology Diversity $\rightarrow$ Project Performance & -0.122 & -0.125 & 0.047 & 2.570 & $0.010 * *$ \\
\hline
\end{tabular}

Note: $* *$ significant at $\alpha=0.01 ; *$ significant at $\alpha=0.05$

Table 11. Total Indirect Effect

\begin{tabular}{|c|c|c|c|c|c|}
\hline & $\begin{array}{l}\text { Original } \\
\text { Sample }(\mathbf{O})\end{array}$ & $\begin{array}{l}\text { Sample } \\
\text { Mean (M) }\end{array}$ & $\begin{array}{l}\text { Standard } \\
\text { Deviation } \\
\text { (STDEV) }\end{array}$ & $\begin{array}{l}\text { t-statistics (| } \\
\text { O/STDEV |) }\end{array}$ & p-values \\
\hline $\begin{array}{l}\text { Work Diversity } \rightarrow \text { Task Conflict } \rightarrow \text { Project } \\
\text { Performance }\end{array}$ & 0.047 & 0.047 & 0.037 & 1.275 & 0.203 \\
\hline $\begin{array}{l}\text { Social Diversity } \rightarrow \text { Task Conflict } \rightarrow \text { Project } \\
\text { Performance }\end{array}$ & -0.046 & -0.007 & 0.058 & 0.798 & 0.425 \\
\hline $\begin{array}{l}\text { Social Diversity } \rightarrow \text { Emotional Conflict } \rightarrow \text { Project } \\
\text { Performance }\end{array}$ & -0.021 & 0.016 & 0.066 & 0.326 & 0.745 \\
\hline $\begin{array}{l}\text { Ideology Diversity } \rightarrow \text { Emotional Conflict } \rightarrow \\
\text { Project Performance }\end{array}$ & -0.122 & -0.125 & 0.047 & 2.570 & $0.010^{* *}$ \\
\hline
\end{tabular}

Note: ${ }^{* *}$ significant at $\alpha=0.01 ; *$ significant at $\alpha=0.05$

Table 12. Specific Indirect Effect

\subsection{Discussion}

\subsubsection{Insights}

In this study, we took an approach similar to that of the diversity study by Liang et al. (2007) with several key differences, namely: (a) we replaced the "value diversity" variable (35 items developed by O’Reilly III et al. (1991) with the more recent, emerging construct of "ideological diversity"; (b) we broadened the demographic coverage of ethnicity, as suggested by Liang et al. (2007); (c) we used data from the unique context of Indonesian start-up firms; and (d) we collected data with a much larger sample size (16 vs. 102 project teams). In effect, we obtained different results as described in the following.

The major key finding that differentiates this from earlier studies is the statistically significant indirect impact of the newly introduced variable of "ideological diversity" on "project performance", as fully moderated by "emotional conflict". Specifically, a positive linkage was found between "ideological diversity" and "emotional conflict" and a negative association was evident for "emotional conflict" and "performance". Consistent with the variable operationalization, this finding can be interpreted to reflect the fact that in Indonesian firms: (a) the more ideologically polarized is the project team, the greater is the perceived emotional conflict among team members; (b) perceived emotional conflict has a significant detrimental effect on project performance; and (c) emotional conflict mediates the association between "ideological diversity" and "performance". 
We found neither "task" nor "emotional" conflict variation to be associated with or originate from "social diversity" in the form of age, gender, ethnicity, or religion. This finding is rather unique when compared to those of previous studies, and we propose some possible explanations.

First, the strong collectivist culture in Indonesia (score for individualism:14, low score vs. USA 91 (Insights, 2018)) may lessen the effect of social diversity on conflict (Williams \& O'Reilly, 1998). Cross-cultural scholars argue that, in some ways, culture may affect individuals and team behavior. A high degree of cultural collectivism suggests a preference for collective well-being over individual welfare. In a project team setting, people are expected to prioritize the team's interests and promote selflessness. These values could then be decoded by individuals, and certain behaviors follow, i.e., people will tend to be less assertive, with an emphasis on face-saving, unity, and harmony. Team members would rather fit in with the group than stand out, which serves to restrain any heightening of conflict.

Secondly, in addition to the rather generic cultural justifications just described, the more progressive characteristics of start-up employees may result in higher tolerance of social diversity, thus dampening its effect on possible conflicts. This progressive, open-minded tendency may be attributable to: (a) project team members in start-ups being predominantly well-educated; (b) the occurrence of self-selection whereby more progressive individuals have a tendency to join emerging start-up industries characterized by higher risk-higher rewards, whereas their less progressive counterparts tend toward traditional/conventional jobs; (c) team members are mostly exposed to urban environments in Indonesia, which are characterized by higher tolerance toward heterogeneity of age/gender/ethnicity/religion.

Another important finding is that "work diversity" positively affected "task conflicts", but "task conflict" itself did not affect performance. The link between "work diversity" and "task conflicts" seems inconsistent with previous assertions about the effect of a collectivist culture in dampening this association. We argue that this case is substantially different. We speculate that differences in tenure, academic background, and work area could generate lively intellectual, task-related debates in project teams, which are seen by members as impersonal and posing no risk of interference with or disruption of the established social harmony.

Our findings suggest that the expectedly productive task conflicts within teams could not effectively be translated into substantively important solutions. The absence of a relationship between "task conflict" and "performance" is compelling, because it runs against the common belief of the positive nature of task conflict in open-ended, non-routine tasks (i.e., in projects) (Guillaume, Dawson, Otaye-Ebede, Woods \& West, 2017). Task conflict has been considered to contribute to broadening the horizon of collective knowledge and strengthening outside networks, which could result in more effective creative problem solving.

We speculate that some adverse conditions in the start-ups contributed to this situation, as follows. First, with respect to the process of creative thinking and problem solving, project team members in start-up firms encounter at least three challenges: (a) at the individual level, there is limited experience and expertise, (b) at the team level, there is limited complementarity of substantive knowledge/skills, and (c) there is an inability to bring in sufficiently diverse outside networks. As such, while the level of task diversity and task conflict may be considered high in a project team, they cannot achieve synergy to produce useful collective knowledge, creativity, and resource networks. In other words, the collective output cannot sufficiently match the typical highly complex problems that must be resolved. Secondly, the extreme time constraint on typical start-up projects may hinder deliberative discussion processes, which are time consuming, as the individuals on the teams have insufficient time to engage in deep thinking. With multiple projects being performed simultaneously, start-up employees are more likely than not to multi-task, which disrupts the necessary creative flow of thought. From a practical viewpoint, the ineffectiveness of this process must be addressed.

The evidence of significant associations between "ideological diversity" and "emotional conflict" and "performance" prompts an intriguing speculation that ideological polarization is too tense a situation to be moderated by cultural norms (e.g. collectivism) or the progressive leanings of the collective of individuals in project teams. This situation becomes very important from a practical perspective, because higher degrees of ideological diversity produce an increasingly net-negative effect on performance. While this issue is beyond the scope of this study, some possible 
solutions can be noted. The most direct approach to addressing this problem may be reducing the ideological polarization of team members by the purposeful selection or screening of prospective project team members during team formation. This option, however, seems infeasible from a technical standpoint, as the project sponsors in startups do not have a sufficiently wide pool of talent for such selection. Furthermore, this approach could generate controversy by being seen by employees and stakeholders as a politically/ideologically motivated decision that would give rise to favoritism. As such, more feasible interventions for this adverse condition must be considered.

\subsubsection{Contributions}

This study offers both academic and practical contributions to the field. Academically, a theoretical framework is provided that reflects the latest conceptual development in research related to diversity and team composition, and incorporates two major research camps on diversity theory. This framework also introduces two types of a process-oriented mediating variables related to conflict. Various moderating variables were also considered but dropped after careful theoretical consideration. This study also extends the body of theoretical knowledge by introducing the emerging social phenomenon of ideological diversity. The conceptual model was empirically tested in the specific occupational context of project teamwork in start-up firms in the unique cultural setting of Indonesia. As such, we applied diversity concepts that have been primarily developed for the Western/developed nation perspective to the novel realm of an Eastern/developing nation. As pointed out by Williams and O'Reilly (1998), collective culture could have moderating effects on the study of diversity. Moreover, Roberson et al. (2017) asserted that diversity studies should "at least consider the boundary conditions created by the cultural context in which studies are conducted” (page: 495).

Accordingly, we add new knowledge to the team-diversity literature by specifically focusing on a unique setting, i.e., an Eastern developing nation characterized by high collectivism and rich in multiple aspects of diversity. The evidence obtained from our study represents a significant departure from the contemporary body of knowledge on team diversity. Current knowledge on team diversity has been mainly built upon the perspectives and empirical data of Western developed countries.

From a practical standpoint, this study offers insights for the executives, managers, and employees of start-up firms in developing nations with rich cultural diversity. It provides evidence of the possible detrimental effect of extreme ideological polarization of team members on project performance via emotional conflict. Ideologically polarized team members and the presence of cliques or factions seem to increase emotional conflict, which reduce the collective performance of the team.

\section{Conclusions}

In this study, we developed and tested a theoretical model that contributes to our understanding of the performance of start-up project teams with respect to diversity within the unique setting of Indonesian start-up firms. We found emotional conflict to have a statistically significant mediating effect on the association between ideological diversity and team performance. A high degree of ideological diversity in a team seems to be detrimental to team performance.

The study results also provide initial evidence for the possible moderating impact of cultural aspects (e.g., collectivism), the characteristics of start-up team members (e.g., openness), and the occupational characteristics of start-up firms (e.g., extreme time constraint) on the association of different types of diversity, conflict, and performance. This impact seems to differ from one linkage to another.

Specifically, based on the empirical evidence obtained, we speculate that cultural collectivism is an effective intervening variable that could lessen conflict originating from social diversity within the team, but not outside of it. However, we found cultural collectivism to have no dampening effects on either the work diversity-task conflict linkage or the ideological diversity-emotional conflict. Instead, other intervening variables, as noted above, are more prominent in such cases. Further study is necessary to confirm these findings.

We highlighted the academic contributions as well as insights for practitioners working in similar settings. Some possible follow-on studies are also suggested. 
Some limitations of this study are as follows. Compared to previous studies, e.g., that by Liang et al. (2007), the sample size of this study was significantly larger. Nevertheless, we recognize that the sample size was still rather small and comprises one of the study's methodological limitations. Another limitation is the inherent weaknesses of the PLS approach, namely: (a) its application is not very suitable to confirmatory analysis (hypothesis testing) because it inclines toward prediction (Hair et al., 2011) and (b) no global measure of the goodness of model fit is available.

Some possible future works are as follows. First, it will be important to follow-up on the initial findings of this study. Specifically, a formal and explicit examination is needed of the role played by: (a) collectivism and other cultural aspects in the diversity-conflict linkage; (b) the attributes of individuals (e.g., openness/progressiveness of start-up employees) with respect to the diversity-conflict association; (c) work conditions in start-ups (e.g., time constraints, multi-tasking) with respect to the efficacy of task diversity and task conflict on improving performance; and (d) other aspects related to the resolution of productive task conflicts in start-ups.

As mentioned above, in this study, various possible moderating variables/contexts were considered during our theoretical deliberation but were ultimately excluded. Apart from data homogeneity (not enough data variation to be examined), the reason for their exclusion was to ensure a more balanced perspective between comprehensiveness and simplicity-parsimony. In future work, much larger sample sizes and greater data heterogeneity are warranted to enable the inclusion of contextual variables. For instance, within the perspective of decision theory, the complexity of projects is a serious candidate for having a moderating effect. Although earlier studies that included project complexity, i.e., (Horwitz \& Horwitz, 2007), found no significant moderating effect, the concept and measures of complexity have progressed significantly since then. Recent studies on various topics have highlighted the importance of project complexity as a contextual variable (e.g., (Ellinas, Allan \& Johansson, 2018; Gao, Chen, Wang \& Wang, 2018; Hartono, 2018; Maylor \& Turner, 2017). Furthermore, from a social identity standpoint, as mentioned earlier, the impacts of cultural dimensions on diversity also deserve further investigation, as proposed by Roberson et al. (2017). The inclusion of moderating variables could facilitate a formal examination of possible managerial interventions. This will be especially important in enhancing the practical contributions of studies in addressing the negative impacts of ideological polarization.

Future studies that offer a more fundamental breakthrough may also be required. For instance, studies on the re-conception and re-classification of diversity, e.g., (Van Knippenberg \& Mell, 2016), are worth pursuing. Moreover, the inclusion of other major schools of thoughts such as social justice theory is warranted.

\section{Declaration of Conflicting Interests}

The authors declare no potential conflicts of interest with respect to the research, authorship, and/or publication of this article.

\section{Funding}

The authors received financial support by a 2019 research grant was provided by the Department of Mechanical and Industrial Engineering, Faculty of Engineering, Universitas Gadjah Mada.

\section{References}

Abrams, D., \& Hogg, M.A. (1990). An introduction to the social identity approach. Social identity theory: Constructive and critical advances, 1-9. https:/ / doi.org/10.4324/9780203135457

Abrams, D., \& Hogg, M.A. (2006). Social identifications: A social psychology of intergroup relations and group processes. Routledge. https://doi.org/10.4324/9780203135457

Aspinall, E. (2019). Indonesia's new era of ideological competition. Inside Story. Available at: https://insidestory.org.au/indonesias-new-era-of-ideological-competition/

Bagozzi, R.P., \& Yi, Y. (1988). On the evaluation of structural equation models. Journal of the academy of marketing science, 16(1), 74-94. https://doi.org/10.1007/BF02723327

Bowers, C.A., Pharmer, J.A., \& Salas, E. (2000). When member homogeneity is needed in work teams: A metaanalysis. Small group research, 31(3), 305-327. https://doi.org/10.1177/104649640003100303 
Chan, D. (1998). Functional relations among constructs in the same content domain at different levels of analysis: A typology of composition models. Journal of applied psychology, 83(2), 234. https://doi.org/10.1037/00219010.83.2.234

CIA (Central Intelligence Agency) (2019). The World Factbook. Available at: https://www.cia.gov/library/publications/the-world-factbook/ (Accessed: July 2019)

Cox, T.H., \& Blake, S. (1991). Managing cultural diversity: Implications for organizational competitiveness. Academy of Management Perspectives, 5(3), 45-56. https://doi.org/10.5465/ame.1991.4274465

de Mol, E., Khapova, S.N., \& Elfring, T. (2015). Entrepreneurial team cognition: A review. International Journal of Management Reviews, 17(2), 232-255. https://doi.org/10.1111/ijmr.12055

Ellinas, C., Allan, N., \& Johansson, A. (2018). Toward project complexity evaluation: A structural perspective. IEEE Systems Journal, 12(1), 228-239. https:/ / doi.org/10.1109/JSYST.2016.2562358

Everett, J.A.C. (2013). The 12 Item Social and Economic Conservatism Scale (SECS). PLoS ONE, 8(12), 1-11. https://doi.org/10.1371/journal.pone.0082131

Fornell, C., \& Larcker, D.F. (1981). Evaluating structural equation models with unobservable variables and measurement error. Journal of marketing research, 18(1), 39-50. https://doi.org/10.1177/002224378101800104

Gao, N., Chen, Y., Wang, W., \& Wang, Y. (2018). Addressing Project Complexity: The Role of Contractual Functions. Journal of Management in Engineering, 34(3), 04018011. https://doi.org/10.1061/(ASCE)ME.19435479.0000613

Garson, D. (2016). Partial least squares (PLS-SEM). Asheboro, NC: Statistical Publishing.

Giardino, C., Unterkalmsteiner, M., Paternoster, N., Gorschek, T., \& Abrahamsson, P. (2014). What do we know about software development in startups? IEEE software, 31(5), 28-32. https://doi.org/10.1109/MS.2014.129

Guetzkow, H., \& Gyr, J. (1954). An analysis of conflict in decision-making groups. Human relations, 7(3), $367-382$. https://doi.org/10.1177/001872675400700307

Guillaume, Y.R., Dawson, J.F., Otaye-Ebede, L., Woods, S.A., \& West, M.A. (2017). Harnessing demographic differences in organizations: What moderates the effects of workplace diversity? Journal of Organizational Behavior, 38(2), 276-303. https://doi.org/10.1002/job.2040

Hair, J.F., Black, W.C., Babin, B., Anderson, R.E., \& Tatham, R.L. (2006). Multivariate Data Analysis (6th ed.). Upper Saddle River, NJ: Pearson Education, Inc.

Hair, J.F., Ringle, C.M., \& Sarstedt, M. (2011). PLS-SEM: Indeed a silver bullet. Journal of Marketing theory and Practice, 19(2), 139-152. https://doi.org/10.2753/MTP1069-6679190202

Harrison, D.A., \& Klein, K.J. (2007). What's the difference? Diversity constructs as separation, variety, or disparity in organizations. Academy of management review, 32(4), 1199-1228. https://doi.org/10.5465/amr.2007.26586096

Hartono, B. (2018). From project risk to complexity analysis: a systematic classification. International Journal of Managing Projects in Business, 11(3), 734-760. https:/ / doi.org/10.1108/IJMPB-09-2017-0108

Hartono, B., Sulistyo, S., \& Umam, M. (2019). Leadership profiles of successful project managers in Indonesia. Journal of Industrial Engineering and Management, 12(2), 274-301. https:/ / doi.org/10.3926/jiem.2735

Hartono, B., Sulistyo, S.R., Chai, K.H., \& Indarti, N. (2019). Knowledge Management Maturity and Performance in a Project Environment: Moderating Roles of Firm Size and Project Complexity. Journal of Management in Engineering, 35(6), 04019023. https://doi.org/10.1061/(ASCE)ME.1943-5479.0000705

Henseler, J. (2010). On the convergence of the partial least squares path modeling algorithm. Computational statistics, 25(1), 107-120. https://doi.org/10.1007/s00180-009-0164-x

Heywood, A. (2004). Political Theory: An Introduction (3rd ed.). Boston, MA: McMillan International. 
Horwitz, S.K., \& Horwitz, I.B. (2007). The effects of team diversity on team outcomes: A meta-analytic review of team demography. Journal of management, 33(6), 987-1015. https://doi.org/10.1177/0149206307308587

Hulland, J. (1999). Use of partial least squares (PLS) in strategic management research: A review of four recent studies. Strategic management journal, 20(2), 195-204. https://doi.org/10.1002/(SICI)1097-0266(199902)20:2<195::AID$\mathrm{SMJ} 13>3.0 . \mathrm{CO} ; 2-7$

Hunt, V., Layton, D., \& Prince, S. (2015). Diversity matters. McKinsey \& Company, 1, 15-29.

Insights, H. (2018). Country comparison. Available at: https://www.hofstede-insights.com/country/indonesia/ (Accessed: August 2019)

Jehn, K.A. (1994). Enhancing effectiveness: An investigation of advantages and disadvantages of value-based intragroup conflict. International journal of conflict management, 5(3), 223-238. https://doi.org/10.1108/eb022744

Jehn, K.A. (1995). A multimethod examination of the benefits and detriments of intragroup conflict. Administrative science quarterly, 256-282. https://doi.org/10.2307/2393638

Jehn, K.A., Northcraft, G.B., \& Neale, M.A. (1999). Why differences make a difference: A field study of diversity, conflict and performance in workgroups. Administrative science quarterly, 44(4), 741-763.

https://doi.org/10.2307/2667054

Liang, T.P., Liu, C.C., Lin, T.M., \& Lin, B. (2007). Effect of team diversity on software project performance. Industrial Management \& Data Systems, 107(5), 636-653. https://doi.org/10.1108/02635570710750408

Mantel, S.J.J., Meredith, J.R., Shafer, S.M., \& Sutton, M.M. (2008). Project Management in Practice (3rd ed.). New York: John Wiley \& Sons.

Marcoulides, G.A., \& Saunders, C. (2006). Editor's comments: PLS: a silver bullet? MIS quarterly, III-IX. https://doi.org/10.2753/MTP1069-6679190202

Maylor, H., \& Turner, N. (2017). Understand, reduce, respond: project complexity management theory and practice. International Journal of Operations \& Production Management, 37(8), 1076-1093. https://doi.org/10.1108/IJOPM-052016-0263

Nidumolu, S. (1995). The effect of coordination and uncertainty on software project performance: residual performance risk as an intervening variable. Information systems research, 6(3), 191-219.

https://doi.org/10.1287/isre.6.3.191

Nurcahyo, R., Akbar, M.I., \& Gabriel, D.S. (2018). Characteristics of startup company and its strategy: Analysis of Indonesia fashion startup companies. International Journal of Engineering \& Technology, 7(2.34), 44-47. https://doi.org/10.14419/ijet.v7i2.34.13908

O’Reilly III, C.A., Chatman, J., \& Caldwell, D.F. (1991). People and organizational culture: A profile comparison approach to assessing person-organization fit. Academy of Management Journal, 34(3), 487-516. https://doi.org/10.5465/256404

Ouimet, P., \& Zarutskie, R. (2014). Who works for startups? The relation between firm age, employee age, and growth. Journal of financial Economics, 112(3), 386-407. https://doi.org/10.1016/j.jfineco.2014.03.003

Pelled, L.H. (1996). Demographic diversity, conflict, and work group outcomes: An intervening process theory. Organization science, 7(6), 615-631. https://doi.org/10.1287/orsc.7.6.615

Philippe, S.N. (2013). Millenials and Attitudes Towards Work-Life Balance.

Pinto, J.K., \& Slevin, D.P. (1988). Project success: definitions and measurement techniques. Project Management Journal, 19(3), 67-73.

PMI (2017). A Guide to the Project Management Body of Knowledge (PMBOK Guide) (6th ed.). Pennsylvania: Project Management Institute, Inc. 
Queiri, A.R., Dwaikat, N., \& Yusoff, W.F.W. (2014). Motivational Methods for Millenials: Balancing Between Workplace Reality and MillenialsExpectations. Paper presented at the International Conference on Economics, Social Sciences and Languages (ICESL'14).

Ramseyer, J.M., \& Rasmusen, E.B. (2015). Measuring voter ideology: descriptive regression measurement of the left-right spectrum. The American Journal of Political Science, 56, 34-51.

Ringle, C.M., Wende, S., \& Becker, J.M. (2015). SmartPLS 3. Boenningstedt: SmartPLS GmbH.

Ringle, C.M., Wende, S., \& Will, A. (2005). SmartPLS 2.0 (M3) Beta. Hamburg Germany.

Roberson, Q., Ryan, A.M., \& Ragins, B.R. (2017). The evolution and future of diversity at work. Journal of applied psychology, 102(3), 483. https://doi.org/10.1037/ap10000161

Tajfel, H. (1981). Human groups and social categories: Studies in social psychology. CUP Archive.

Tapsell, R. (2019). The polarisation paradox in Indonesia's 2019 elections. New Mandala. Available at: https://www.newmandala.org/the-polarisation-paradox-in-indonesias-2019-elections/

Teachman, J.D. (1980). Analysis of population diversity: Measures of qualitative variation. Sociological Methods \& Research, 8(3), 341-362. https://doi.org/10.1177/004912418000800305

Turner, N., Maylor, H., \& Swart, J. (2015). Ambidexterity in projects: An intellectual capital perspective. International Journal of Project Management, 33(1), 177-188. https://doi.org/10.1016/j.ijproman.2014.05.002

Unterkalmsteiner, M., Abrahamsson, P., Wang, X., Nguyen-Duc, A., Shah, S., Bajwa, S. S. et al. (2016). Software startups-a research agenda. e-Informatica Software Engineering Journal, 10(1). https://doi.org/10.5277/e-Inf160105

Van Knippenberg, D., \& Mell, J.N. (2016). Past, present, and potential future of team diversity research: From compositional diversity to emergent diversity. Organizational Behavior and Human Decision Processes, 136, 135-145. https://doi.org/10.1016/j.obhdp.2016.05.007

Van Knippenberg, D., \& Schippers, M.C. (2007). Work group diversity. Annu. Rev. Psychol., 58, 515-541. https://doi.org/10.1146/annurev.psych.58.110405.085546

van Veelen, R., \& Ufkes, E.G. (2019). Teaming Up or Down? A Multisource Study on the Role of Team Identification and Learning in the Team Diversity-Performance Link. Group \& Organization Management, 44(1), 38-71. https://doi.org/10.1177/1059601117750532

Wang, H., \& Hanna, S.D. (1997). Does risk tolerance decrease with age? Financial Counseling and Planning, 8(2). https://doi.org/10.2139/ssrn.95489

Webber, S.S., \& Donahue, L.M. (2001). Impact of highly and less job-related diversity on work group cohesion and performance: A meta-analysis. Journal of management, 27(2), 141-162. https://doi.org/10.1177/014920630102700202

Williams, K., \& O’Reilly, C.A. (1998). Demography and diversity in organizations: A review of 40 years of research. Research in organizational behavior, 20(20), 77-140.

Wong, K.K.K. (2013). Partial least squares structural equation modeling (PLS-SEM) techniques using SmartPLS. Marketing Bulletin, 24(1), 1-32.

Wu, G., Zhao, X., Zuo, J., \& Zillante, G. (2019). Effects of team diversity on project performance in construction projects. Engineering, Construction and Architectural Management. https://doi.org/10.1108/ECAM-05-2018-0220

Zhou, W., \& Rosini, E. (2015). Entrepreneurial team diversity and performance: Toward an integrated model. Entrepreneurship Research Journal, 5(1), 31-60. https://doi.org/10.1515/erj-2014-0005 


\section{Appendix A - Variable-Indicator Matrix}

\section{Team Diversity $(\mathrm{X})$}

\begin{tabular}{|c|c|c|c|}
\hline Variable & Indicator Code & Indicator & Response Scale \\
\hline \multirow{3}{*}{$\begin{array}{l}\mathrm{X}_{1}-\text { Work } \\
\text { Diversity }\end{array}$} & $\mathrm{X}_{1.1}-\mathrm{OT}$ & $\begin{array}{l}\text { Time (rounded up in years) that you have worked in your current } \\
\text { start-up }\end{array}$ & \multirow{4}{*}{ Open ended } \\
\hline & $\mathrm{X}_{1.2}-\mathrm{FB}$ & $\begin{array}{l}\text { Your work area (the job or division in which you most often work) in } \\
\text { the start-up }\end{array}$ & \\
\hline & $\mathrm{X}_{1.3}-\mathrm{FOS}$ & Your current or most recent major or field of study & \\
\hline \multirow{4}{*}{$\begin{array}{l}\mathrm{X}_{2}-\text { Social } \\
\text { Diversity }\end{array}$} & $\mathrm{X}_{2.1}-\mathrm{AGE}$ & The year you were born & \\
\hline & $\mathrm{X}_{2.2}-\mathrm{GEN}$ & Your current gender identity & \multirow{3}{*}{ Multiple Choice } \\
\hline & $\mathrm{X}_{2.3}-\mathrm{ETH}$ & The ethnicity that you are part of or feel most attached to & \\
\hline & $\mathrm{X}_{2.4}-\mathrm{REL}$ & The religion or faith system (or lack thereof) with which you identify & \\
\hline \multirow{5}{*}{$\begin{array}{l}\mathrm{X}_{3}- \\
\text { Ideology } \\
\text { Diversity }\end{array}$} & $\mathrm{X}_{3.1}-\mathrm{HUM}$ & $\begin{array}{l}\text { I prefer the utilization of humanistic principles (human rights, law } \\
\text { philosophy, and science) over faith-based values (such as religion and } \\
\text { tradition) in the establishment of laws, social norms, and public } \\
\text { policy. }\end{array}$ & \multirow{5}{*}{$\begin{array}{l}\text { Ordinal, 7-point } \\
\text { Likert Scale, } \\
\text { Close Ended } \\
\text { Question }\end{array}$} \\
\hline & $\mathrm{X}_{3.2}-\mathrm{EGA}$ & $\begin{array}{l}\text { I support the values of egalitarianism, including but not limited to } \\
\text { gender and racial equality, and am accommodating to ethnic diaspora } \\
\text { and pluralism of belief. }\end{array}$ & \\
\hline & $\mathrm{X}_{3.3}-\mathrm{GAY}$ & $\begin{array}{l}\text { I am supportive of the diversity of sexual identity that can be } \\
\text { considered non-conventional or 'queer,' including homosexuality, } \\
\text { bisexuality, or transgenderism (LGBTQ). }\end{array}$ & \\
\hline & $\mathrm{X}_{3.4}-\mathrm{FRE}$ & $\begin{array}{l}\text { I believe that individual freedom and civil liberties such as freedom of } \\
\text { thought, faith, and speech should never be limited by the government } \\
\text { unless absolutely necessary to prevent physical harm or loss of life. }\end{array}$ & \\
\hline & $\mathrm{X}_{3.5}-\mathrm{BOD}$ & $\begin{array}{l}\text { I take in high regard the bodily rights of others and am tolerant of } \\
\text { people's decision in choice of wear or extramarital sexual activity. }\end{array}$ & \\
\hline
\end{tabular}

\section{Intragroup Conflict (Y)}

\begin{tabular}{|c|c|c|c|}
\hline Variable & Indicator Code & Indicator & Response Scale \\
\hline \multirow{5}{*}{$\begin{array}{l}Y_{1}-\text { Task } \\
\text { Conflict }\end{array}$} & $\mathrm{Y}_{1.1}$ & $\begin{array}{l}\text { How often do people in your work unit disagree in their opinions } \\
\text { regarding the work being done? }\end{array}$ & \multirow{10}{*}{$\begin{array}{l}\text { Ordinal, 5-point } \\
\text { Likert Scale, } \\
\text { Close Ended } \\
\text { Questions }\end{array}$} \\
\hline & $\mathrm{Y}_{1.2}$ & $\begin{array}{l}\text { How often do members of your team disagree about how things } \\
\text { should be done? }\end{array}$ & \\
\hline & $\mathrm{Y}_{1.3}$ & $\begin{array}{l}\text { How often do members of your team disagree about which } \\
\text { procedure should be used to do the work? }\end{array}$ & \\
\hline & $\mathrm{Y}_{1.4}$ & $\begin{array}{l}\text { How frequently do conflicts occur with respect to concepts or ideas } \\
\text { in your unit? }\end{array}$ & \\
\hline & $Y_{1.5}$ & How frequent are the arguments in your team task-related? & \\
\hline \multirow{5}{*}{$\begin{array}{l}\mathrm{Y}_{2}- \\
\text { Emotional } \\
\text { Conflict }\end{array}$} & $\mathrm{Y}_{2.1}$ & How much friction or tension is there among members in your unit? & \\
\hline & $Y_{2.2}$ & How much are personality clashes evident in your work unit? & \\
\hline & $Y_{2.3}$ & How often do people get angry while working in your unit? & \\
\hline & $\mathrm{Y}_{2.4}$ & How much jealousy or rivalry is there in your work unit? & \\
\hline & $\mathrm{Y}_{2.5}$ & How frequent are the arguments in your team non-task related? & \\
\hline
\end{tabular}


3. Performance (Z)

\begin{tabular}{|c|c|c|c|}
\hline Variable & Indicator Code & Indicator & Response Scale \\
\hline \multirow{5}{*}{$\begin{array}{l}Z_{1}-\text { Project } \\
\text { Performance }\end{array}$} & $Z_{1.1}$ & This project has/will come in on schedule & \multirow{16}{*}{$\begin{array}{l}\text { Ordinal, 7-point } \\
\text { Likert Scale, } \\
\text { Close Ended } \\
\text { Question }\end{array}$} \\
\hline & $\mathrm{Z}_{1.2}$ & This project has/will come in on budget & \\
\hline & $\mathrm{Z}_{1.3}$ & The project that has been developed works, or looks as if it will work & \\
\hline & $\mathrm{Z}_{1.4}$ & $\begin{array}{l}\text { Given the problem for which it was developed, this project seems to } \\
\text { do the best job of solving that problem, i.e., it was the best choice } \\
\text { among the set of alternatives }\end{array}$ & \\
\hline & $\mathrm{Z}_{1.5}$ & $\begin{array}{l}\text { The results of this project represent a definite improvement in } \\
\text { performance over the way clients used to perform these activities }\end{array}$ & \\
\hline \multirow{7}{*}{$\begin{array}{l}Z_{2}-\text { Client- } \\
\text { Based } \\
\text { Performance }\end{array}$} & $\mathrm{Z}_{2.1}$ & The project will be/is used by its intended clients & \\
\hline & $\mathrm{Z}_{2.2}$ & Important clients directly affected by this project will make use of it & \\
\hline & $\mathrm{Z}_{2.3}$ & $\begin{array}{l}\text { We are confident that non-technical start-up problems will be } \\
\text { minimal, because the project will be readily accepted by its intended } \\
\text { users }\end{array}$ & \\
\hline & $\mathrm{Z}_{2.4}$ & $\begin{array}{l}\text { The client is/was satisfied with the process by which this project is } \\
\text { being/was completed }\end{array}$ & \\
\hline & $\mathrm{Z}_{2.5}$ & $\begin{array}{l}\text { This project has/will directly benefit the intended users either } \\
\text { through increasing efficiency or employee effectiveness }\end{array}$ & \\
\hline & $\mathrm{Z}_{2.6}$ & $\begin{array}{l}\text { Use of this project has/will directly lead to improved or more } \\
\text { effective decision making or performance for the clients }\end{array}$ & \\
\hline & $\mathrm{Z}_{2.7}$ & This project will have a positive impact on those who make use of it & \\
\hline \multirow{4}{*}{$\begin{array}{l}\mathrm{Z}_{3}-\text { Team } \\
\text { Learning }\end{array}$} & $\mathrm{Z}_{3.1}$ & $\begin{array}{l}\text { The team acquired good knowledge about the use of key } \\
\text { technologies }\end{array}$ & \\
\hline & $\mathrm{Z}_{3.2}$ & $\begin{array}{l}\text { The team acquired good knowledge about the use of project } \\
\text { development techniques }\end{array}$ & \\
\hline & $\mathrm{Z}_{3.3}$ & $\begin{array}{l}\text { The team acquired good knowledge on how to support users' } \\
\text { business }\end{array}$ & \\
\hline & $\mathrm{Z}_{3.4}$ & The team acquired good overall knowledge through the project & \\
\hline
\end{tabular}

Journal of Industrial Engineering and Management, 2020 (www.jiem.org)

\section{(ब) (1) (}

Article's contents are provided on an Attribution-Non Commercial 4.0 Creative commons International License. Readers are allowed to copy, distribute and communicate article's contents, provided the author's and Journal of Industrial Engineering and Management's names are included. It must not be used for commercial purposes. To see the complete license contents, please visit https://creativecommons.org/licenses/by-nc/4.0/. 